\title{
Sustainable poverty alleviation and green development in China's underdeveloped areas
}

\author{
GUO Yuanzhi ${ }^{1}$, "LIU Yansui ${ }^{1,2}$ \\ 1. Key Laboratory of Regional Sustainable Development Modeling, Institute of Geographic Sciences and Nat- \\ ural Resources Research, CAS, Beijing 100101, China; \\ 2. College of Resources and Environment, University of Chinese Academy of Sciences, Beijing 100190, China
}

\begin{abstract}
In 2020, the decisive victory of building a moderately well-off society in all aspects means that absolute poverty in rural China has been completely eliminated. Consolidating and expanding the achievements of poverty alleviation and establishing a long-term mechanism to solve relative poverty have become key issues in high-quality development of underdeveloped areas. In this study, human-earth system is employed to analyze the element composition, structural organization and functional state of underdeveloped areas. The results show that poverty in underdeveloped areas stems from the lack of the coupling and coordinating mechanism among human, economic, resource and environmental elements, which is not conducive to transforming the ecological advantages into the advantages of regional development. In the antipoverty stage, underdeveloped areas innovate the human-earth coupling and coordinating mechanism through a series of targeted measures, promote the organic combination of poverty alleviation, ecological conservation and sustainable development, and boost the transformation of regional development and the increase of farmers' incomes. Focusing on the 14th Five-year Plan (2021-2025) and the long-term goal of 2035, governments in underdeveloped areas should make full use of the policy support to explore scientific methods of modern governance and sustainable development. In particular, it is necessary to practice the concept that "clear waters and lush mountains are invaluable assets" and take the road of the ecologicalization of industry and the industrialization of ecology by establishing a policy system of "green land", "green people", "green industry" and "green right", thus building an endogenous growth mechanism of sustainable poverty alleviation and green development in China's underdeveloped areas.
\end{abstract}

Keywords: sustainable poverty alleviation; green development; human-earth system; underdeveloped areas; high-quality development; ecological civilization

Received: 2021-07-28 Accepted: 2021-10-21

Foundation: National Natural Science Foundation of China, No.41931293, No.42001203; Strategic Priority Research Program of Chinese Academy of Sciences, No.XDA23070300

Author: Guo Yuanzhi (1990-), PhD and Assistant Professor, specialized in urban-rural transformation and regional sustainable development. E-mail: guoyz.16b@igsnrr.ac.cn

"Corresponding author: Liu Yansui (1965-), Professor, specialized in human-earth science and rural sustainability. 


\section{Introduction}

Poverty is a complex socio-economic phenomenon, which evolves with the changes of dominant development paradigms (Misturelli and Heffernan, 2010). In terms of its connotation, poverty mainly refers to resource shortage, low income, social exclusion, lack of capacity and deprivation of rights (Duraiappah, 1998; Copestake and Camfield, 2010; Guo et al., 2018). Therefore, poverty is often accompanied by a series of problems, such as hunger, disease, unemployment, terrorism and social conflict (Brainard and Chollet, 2007; Oluwatayo and Ojo, 2018; Ujunwa et al., 2019; Guo and Wang, 2021), which seriously restrict social and economic development in poverty-stricken areas, leading to more people falling into poverty and forming a vicious circle of poverty (Matsuyama, 2010). Against this background, poverty has long been the focus of attention all over the world, and reducing or eradicating poverty has become the common ideal and mission of mankind.

In 2000, 189 countries cosigned the Millennium Declaration at the United Nations (UN) Millennium Summit, and committed to establishing a new global partnership to reduce extreme poverty (World Bank, 2016). With the end of the Millennium Development Goals (MDGs) in 2015, the UN launched the 2030 agenda for sustainable development with poverty eradication as the primary goal to guide global development in 2015-2030 and promote the construction of a community with a shared future for mankind (UN, 2015). Under the guidance of these programmatic documents, countries around the world have made corresponding innovations in system design and made many attempts in antipoverty practices, which greatly alleviate the local poverty situation. However, due to the failure to deal with the relationship between endogenous development and external assistance, it is easy for people who have overcome poverty to return to poverty when external forces withdraw (Faust, 2010; An, 2019). Meanwhile, because of the imbalance between individual poverty alleviation and regional development, poverty alleviation in underdeveloped areas lacks sustained and effective support from regional economic growth and social progress, which restricts the formation of the poor's sustainable development ability (Cobbinah et al., 2013; Zhou and Liu, 2019; Deinne and Ajayi, 2021).

China was once a developing country with the largest poverty-stricken population in the world (Liu et al., 2017; Guo and Liu, 2021). In the long-term process of poverty reduction, the underdeveloped central and western regions, where the poor is concentrated, are also facing the problem of the sustainability of poverty alleviation, which is similar to other developing countries (Liu et al., 2017). To reverse this situation, the Chinese government has issued a series of policies and measures to promote poverty governance from the aspects of top-level design, institutional arrangement and typical practice, thus enhancing the endogenous development capacity of poor people and poverty-stricken areas (Zhou et al., 2018; Guo et al., 2019a). After antipoverty stages such as relief-type poverty alleviation under planned economy, poverty alleviation through structural reform, development-oriented poverty alleviation, National Eight-Seven Poverty Alleviation Plan, entire-village advancement poverty alleviation and targeted poverty alleviation, China has developed a sustainable antipoverty road with Chinese characteristics (Liu et al., 2018; Guo et al., 2019a; Fu et al., 2021). In 2020, China successfully achieved the goal of eradicating absolute poverty under the current standards as scheduled, which was ten years ahead of schedule for the goal of "no poverty" in the UN sustainable development agenda and made great contributions to 
global poverty alleviation (Guo et al., 2018; Guo and Liu, 2021).

Although absolute poverty in China's underdeveloped areas has been eliminated, relative poverty will continue to exist for a long time (Guo et al., 2018). Meanwhile, with the evolution of principal social contradiction, the focus of regional development in underdeveloped areas has changed from bottom-line poverty alleviation to high-quality rural revitalization (Guo et al., 2019b; Ge and Lu, 2021; Guo and Liu, 2021). Essentially, poverty alleviation and rural revitalization are two different but closely related strategies (Guo et al., 2019b). The underdeveloped central and western China should strive to improve the formed sustainable antipoverty mechanism according to local conditions and enhance the endogenous growth momentum, which not only consolidate the basic support for individuals and regions to overcome poverty but also promote regional development to a higher level. According to the national major function-oriented zone planning, the underdeveloped central and western regions are important ecological barriers in China, which are featured by prominent ecological vulnerability (Fan et al., 2012). Under the background of the new normal, which means economic development changes from scale-speed type to quality-efficiency type (Yu and Xing, 2021), the contradiction between economic growth and ecological protection has become a prominent challenge for the development of underdeveloped areas (Liu et al., 2017, 2018; Luo et al., 2019). Therefore, following the concept of ecological civilization, practicing the principle that "clear waters and lush mountains are invaluable assets" and innovating green development path and mode have become inevitable choices for the sustainable development of China's underdeveloped areas in the new era.

Regional development is the comprehensive result of human-earth interaction (Liu, 2020), and poverty and backwardness essentially come from the contradiction and conflict of human-earth system (Guo et al., 2018). Therefore, analyzing the practice and mechanism of poverty alleviation in underdeveloped areas and exploring the path and mode of green development from the perspective of human-earth system science are of great significance to optimize human-earth relationship in underdeveloped areas and realize regional high-quality development. Based on the investigation of the third-party evaluation on the effectiveness of national targeted poverty alleviation from 2016 to 2020, this study deeply analyzes the characteristics of human-earth system in China's underdeveloped areas, discusses the practice and mechanism of sustainable poverty alleviation in the decisive stage of poverty alleviation, and puts forward the path and mode of green development in underdeveloped areas in the new era. The main contribution of this study is to explore the causes of underdeveloped areas and investigate the mechanism of sustainable poverty alleviation from the perspective of human-earth system science, and then put forward the green development path and mode that are conducive to realizing element coupling, structure optimization and function improvement of human-earth system in underdeveloped areas.

\section{Understanding underdeveloped areas: A perspective of human-earth system}

\subsection{Regional human-earth system}

Human-earth relationship, which is accompanied by the emergence and development of mankind, refers to the interaction between human activities and natural environment, and 
has always been the core of geographical research (Wu, 1991). Regional human-earth system is an organic whole with special structure, function and interregional connection formed by the coupling of human activities and natural environment in a specific region, and is mainly composed of resource elements, environmental elements, human elements and economic elements (Guo et al., 2018; Liu, 2020). The former two are the primary geographical elements with relative stability, which provide basic support for regional development and restrict the depth, breadth and speed of human activities; the latter two are the secondary geographical elements with strong plasticity, which are the most active and changeable elements in regional development, and gradually become the main forces driving the evolution of regional human-earth system due to the increasing role of human activities on the development of natural environment (Combes et al., 2008). In the process of regional development, human-earth system presents the evolutionary trends of element upgrading, structural complexity, functional diversification and space expansion. Meanwhile, with the enhancement of interregional contacts and the improvement of system openness, regional human-earth system is increasingly restricted and affected by the external environment, and breaks through the regional restrictions in space, becoming a part of the larger human-earth system.

Through material circulation, energy flow and information exchange, the internal elements of regional human-earth system and their interactions with external environment continuously strengthen the dissipative structure of the whole system and provide a driving force for regional development, thus promoting the evolution of system function and status (Guo et al., 2018). Therefore, the ultimate goal of regional development is to build a system structure and function suitable for the development of productivity in the process of understanding, utilizing and transforming natural systems, continuously optimizing human-earth relationship and promoting regional human-earth system to realize a state leap in "transformation-adaptation" and "restriction-transcendence". However, when conflicts occur within the system and the situation continues to deteriorate, a trend of "destruction-decline" of the human-earth system will emerge. In other words, when various elements constitute a reasonable and orderly structure according to certain rules, regional human-earth system shows obvious adaptability to the external environment, which promotes the healthy and sustainable development of the system (Cheng, 2006), while if the element combination and the structure formed by them are unreasonable, regional human-earth system will continue to decline and show obvious vulnerability, resulting in stagnation or even decline of regional development (Li et al., 2017; Liu et al., 2020a).

\subsection{Characteristics of underdeveloped areas}

The coupling and evolution of human-earth system constitute the whole content of regional development (Guo et al., 2018). Therefore, underdeveloped areas are the result of the imbalance and conflict of regional human-earth system, and the evolution of underdeveloped areas is featured by insufficient resources, poor environment, biased institution and backward economy.

\subsubsection{Insufficient resources}

Here, resources refer to natural elements in a narrow sense, that is, natural substances that human beings can obtain and use for production and life. Therefore, resources have the dual 
attributes of nature and society, and are the basic factors determining the level of regional development (Guo et al., 2018). On the one hand, resource elements are the material basis and basic premise of human survival and development; on the other hand, as an important object of human activities, resource elements play a critical role in regional development through human labor (Wu, 1991). In China, there are obvious disadvantages in the resource endowment of underdeveloped areas, which are mainly manifested in insufficient quantity and unreasonable combination. Taking water and land resources as an example, their deficiencies in the initial stage of regional development make regional agricultural development lag behind, lead to the lack of support for industrialization and urbanization, and restrict regional development to a higher level. Spatially, underdeveloped areas in the south are mainly restricted by land resources, while those in the north are mainly restricted by water resources (Zhou and Fan, 2015). With the improvement of social productivity and the advancement of science and technology, the connotation of natural resources is expanding. However, due to the lack of key natural resources, the new resources have not yet become a strong driving forces for social and economic development in underdeveloped areas.

\subsubsection{Poor environment}

Environment refers to the earth's surface environment composed of atmosphere, hydrosphere, biosphere and lithosphere, which restricts the development of human activities through its bearing capacity. Spatially, the underdeveloped central and western regions are the main carriers of the national ecological security strategic pattern. The regional major functions of ecological services and construction determine that they do not have the conditions for large-scale population agglomeration and high-intensity industrial development (Fan et al., 2020). However, the huge population makes the interference of various production and living activities on the natural environment persist, and regional development is facing prominent environmental problems such as soil erosion, land degradation and sharp decline of biodiversity, which exacerbates the vulnerability of ecological environment (Liu et al., 2018; Zhou et al., 2020). Meanwhile, the landform dominated by plateaus, mountains and hills makes infrastructure construction difficult and costly, and problems such as insufficient quantity and incomplete function of public service facilities are prominent. In addition, the geographical barrier effect makes the underdeveloped areas isolated or semi-isolated for a long time, which restricts the exertion of their own comparative advantages and the input of external factors. The analysis of typical underdeveloped areas in China, concentrated contiguous areas with special difficulties, shows that the areas with a slope greater than 15 degrees account for $37.8 \%$, and the environmental constraints of regional development are extremely significant (Table 1).

\subsubsection{Biased institution}

At the beginning of reform and opening up, the unbalanced development strategy was adopted by Chinese government to concentrate limited resources to develop the national economy, gradually forming a regional pattern of developed eastern regions and underdeveloped central and western regions (Yang, 1990; He et al., 2017). Upon entering the 21st century, the Chinese government has issued a series of policies and measures to accelerate the development of underdeveloped areas, but there is still a big gap between underdeveloped areas and developed areas in infrastructure, public services, human capital, etc. To 
Table 1 The main natural features of the concentrated contiguous areas with special difficulties in China

\begin{tabular}{|c|c|}
\hline Areas & Main natural features \\
\hline Liupan Mountain Area & $\begin{array}{l}\text { Ravines and gullies crisscross, sparse vegetation, serious soil erosion, fre- } \\
\text { quent occurrence of geologic hazard }\end{array}$ \\
\hline Qinba Mountain Area & Complex environment, outstanding biodiversity \\
\hline Wuling Mountain Area & Karst landform, frequent occurrence of geologic hazard \\
\hline Wumeng Mountain Area & $\begin{array}{l}\text { Frequent occurrence of geologic hazard, high mountains and precipitous } \\
\text { paths, poor soil }\end{array}$ \\
\hline $\begin{array}{l}\text { Rocky DesertifiedArea in Yunnan- } \\
\text { Guizhou-Guangxi }\end{array}$ & Complex terrain, fragile ecology, frequent occurrence of geologic hazard \\
\hline $\begin{array}{l}\text { Border Mountainous Area of Western } \\
\text { Yunnan }\end{array}$ & Fragile ecology, frequent occurrence of geologic hazard \\
\hline $\begin{array}{l}\text { Mountainous Area in the South of } \\
\text { Greater Hinggan Range }\end{array}$ & Cold climate, vast land with sparse population \\
\hline Yanshan-Taihang Mountain Area & Broken surface, fragile ecology, frequent occurrence of geologic hazard \\
\hline Luliang Mountain Area & Undulating terrain, poor soil, serious drought and soil erosion \\
\hline Dabie Mountain Area & Low forest coverage, serious soil erosion \\
\hline Luoxiao Mountain Area & Unbalanced ecology, serious soil erosion \\
\hline Four Prefectures in Southern Xinjiang & $\begin{array}{l}\text { Arid climate, frequent occurrence of geologic hazard, extremely fragile } \\
\text { ecology }\end{array}$ \\
\hline Tibetan Area in Four Provinces & Pervasive mountains and valleys, frequent occurrence of geologic hazard \\
\hline Tibet & High-cold area, complex terrain and climate \\
\hline
\end{tabular}

Source: Liu et al., 2016.

optimize the territorial development pattern, the government issued and implemented the National Major Function-Oriented Zone Planning in 2010. In this plan, most of the central and western regions are designated as agricultural and ecological areas, which means that socioeconomic development in these areas is restricted or prohibited. In addition, influenced by deep- rooted hukou system and urban-biased system, the support of rural development to urban development is weak, and the driving ability of urban development to rural development is limited, forming a prominent urban-rural dual structure in underdeveloped areas (Wang et al., 2016). Due to the unreasonable system and biased policies, underdeveloped areas have obvious weaknesses and disadvantages in human elements, and their comparative advantages have not been effectively transformed into the advantages of regional development; also, Matthew effect restricts the development of underdeveloped areas to a higher level.

\subsubsection{Backward economy}

The core of regional development is economic growth, that is, promoting the transformation and upgrading of industrial structure and expanding economic aggregate. Due to location disadvantages, the economic development mode of underdeveloped areas is extensive, and the industry presents the characteristics of low level and unreasonable structure. Extensive economic development mode means that regional economic development mainly depends on the input of natural resources and cheap labor, which is essentially an unsustainable and inefficient expansion. In general, China's underdeveloped areas can be divided into areas dominated by agriculture and those dominated by single resource-based industries (Yang, 1997). In terms of the former, the low-level productive forces make a large number of lands, labor and other factors fixed in inefficient agricultural production, and the agricultural surplus labor force cannot be effectively transferred to nonagricultural industries, especially the 
service industry, which makes its support for industrialization and urbanization in underdeveloped areas weak. Regarding the latter, underdeveloped areas have established an industrial system based on mineral resources and dominated by heavy industry. However, due to the self-service and self-circulation characteristics of heavy industry, its driving effect on regional development is limited, and the phenomenon of "enriching regions but not enriching people" is common. In addition, the large-scale and predatory exploitation of mineral resources intensifies the local ecological and environmental pressure, resulting in serious problems such as land degradation and vegetation destruction (Liu et al., 2003; Gong et al., 2013); also, it will lead to the problem of resource exhaustion.

\section{Sustainable antipoverty practice and mechanisms in underdeveloped areas}

\subsection{Sustainable antipoverty practice}

The prominent human-earth conflict makes the unsustainability of regional development in underdeveloped areas remarkable, which is significantly manifested in the problem of poverty. Although the Chinese government has taken a series of policies and measures to promote poverty governance, the long-term human-earth conflict in underdeveloped areas has not fundamentally changed due to unreasonable human activities and fragile geographical environment (Liu et al., 2017). The vulnerability of human-earth system makes the people who have overcome poverty vulnerable to return to poverty, resulting in the persistence of poverty in underdeveloped areas. Meanwhile, the islanding effect of the distribution of the poor and the marginal diminishing effect of antipoverty resources are becoming increasingly prominent with the advancement of poverty alleviation (Liu et al., 2017; Guo et al., 2019a). In this context, underdeveloped areas have developed an antipoverty practice system with Chinese characteristics according to the causes of regional poverty and individual poverty, mainly including industrial development, labor transfer, resettlement, educational development, medical services, ecological construction, policy guarantee, social participation, etc. (Figure 1). By establishing an antipoverty mechanism with the joint efforts of government, market and society, the persistence of antipoverty practice and stability of antipoverty performance are effectively guaranteed to supplement the shortcomings of underdeveloped

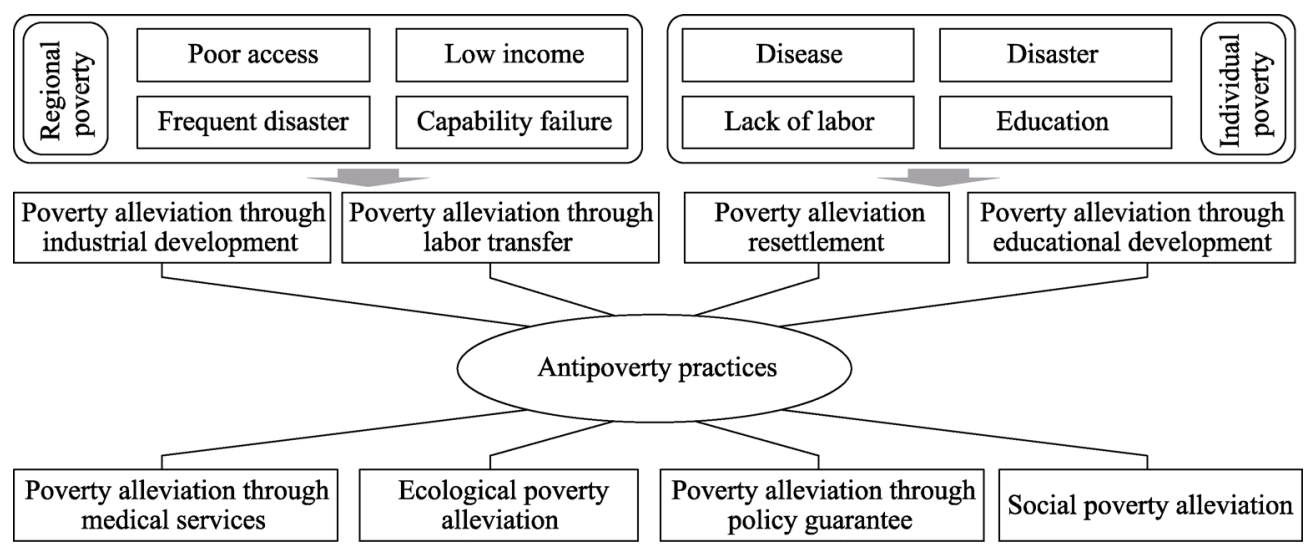

Figure 1 Antipoverty practice system in China's underdeveloped areas 
areas, optimize the human-earth relationship in underdeveloped areas and promote the sustainable development of underdeveloped areas.

Poverty alleviation through industrial development is built on the basis of local resources, and aims to steadily improve the poor's income and optimize their income structure by establishing a market-oriented industrial system with strong driving force for poverty alleviation. The purpose of poverty alleviation through labor transfer is to conduct targeted skills training and employment services according to the characteristics of the poor, help the employed poor achieve stable employment and obtain urban citizenship and the unemployed poor who have the ability and willingness to work participate in labor export. Statistics show that more than $90 \%$ of China's poverty-stricken population have been supported by industrial development and labor transfer, and more than two-thirds of the people who have been lifted out of poverty are realized through exporting labor and developing industries. The target of poverty alleviation resettlement is the poor living in areas with poor natural conditions and bad living environments. On the basis of fully respecting their wishes, the government steadily promotes resettlement, builds public service facilities and infrastructure, and develops characteristic and advantageous industries. During the period of 2016-2020, the Chinese government has invested about 600 billion yuan to resettle 9.81 million poor people in more than 1400 counties in the central and western regions. Among them, 32.2\%, $34.7 \%, 16.00 \%$ and $10.80 \%$ of the poor are respectively distributed in areas with serious shortage of resources and environmental carrying capacity, areas with severe shortage of public service facilities and high construction costs, areas where development is prohibited or restricted by the central government and areas prone to geological disasters.

By constructing educational facilities, improving the level of basic education, developing vocational education and enhancing the service ability of higher education, poverty alleviation through educational development improves the comprehensive quality of the poor, promotes the accumulation of human capital and blocks the intergenerational transmission of poverty in poor areas. The investigation of 72 poverty-stricken counties in 2020 showed that their service level of public education was close to the national average, and the consolidation rate of compulsory education increased from $93.1 \%$ in 2015 to $99.0 \%$. Focusing on the shortage of medical resources, poverty alleviation through healthcare services narrows the gap of regional medical resources and promotes the full coverage of basic public health services by improving the public health system and medical security system, which effectively solve the problems of poverty related to illness. A field investigation at the end of 2020 showed that the poverty-stricken population had been fully covered by basic medical treatment, critical illness insurance and medical assistance in 2020, and the proportion of hospitalization compliant medical expenses reimbursed by the poor reached $90.0 \%$; poor counties had achieved full coverage of secondary hospitals, and the three-level medical service system of county-township-village had been continuously improved.

Ecological poverty alleviation aims to deal with the relationship between ecological protection and poverty alleviation, and improve the sustainable development ability of poor areas by strengthening ecological restoration and environmental governance; on this basis, an ecological compensation mechanism is gradually improved to make the poor overcome poverty through participating in ecological protection and construction. From 2016 to 2020, more than 1.1 million poor people with working ability in central and western China have been selected as ecological forest rangers, and each person can get an income of 10,000 yu- 
an a year. Poverty alleviation through social participation aims to give play to the leading and exemplary role of antipoverty programmes, such as antipoverty cooperation between the East and the West and targeted poverty alleviation by central institutions, forming a strong joint force to fight against poverty through the cohesion of all forces. In the process of poverty alleviation, the eastern and western regions of China have gradually formed a cooperation mode with government aid, enterprise cooperation and social assistance, and various typical modes have emerged, such as Fujian-Ningxia cooperation, Shanghai-Yunnan cooperation and Guangdong-Guangxi cooperation. The key of poverty alleviation through policy guarantees is to improve social assistance systems, such as rural minimum living security system, and the care service system for "left-behind children, left-behind woman, left-behind older" and disabled people, thus realizing the integration of poverty alleviation and social security. From 2016 to 2020 , about 20 million poverty-stricken people enjoy minimum living security and special hardship assistance, and more than 24 million people with difficulties and serious disabilities receive living and nursing subsidies.

\subsection{Mechanisms of sustainable poverty alleviation}

Poverty is a multidimensional concept (Alkire et al., 2015). In addition to income, it also includes many non-monetary dimensions, such as education, healthcare and housing (Alkire and Foster, 2011; Fransman and Yu, 2019). Through measures such as overall planning and the innovation of regional coordinated development mechanism, the Chinese government has continuously increased investment in poverty alleviation, promoted the organic combination of poverty reduction with regional industrialization and urbanization, strengthened infrastructure construction and public service support, and effectively improved production and living conditions in underdeveloped areas. Meanwhile, underdeveloped areas actively improve the antipoverty measures and policy system to increase the disposable income of the poor and ensure that the poor have no concerns regarding food and clothing and that their needs for compulsory education, safe housing and basic healthcare are guaranteed (Guo et al., 2019).

In terms of social and economic development in underdeveloped areas, poverty alleviation is the key point, ecological conservation is the basic premise, and sustainable development is the ultimate goal. Based on the resources and environmental bearing capacity, underdeveloped areas employ the concept of marketization to tap regional factor endowment and promote the transformation of ecological factors into production factors and resources into wealth. In particular, relying on the unique ecological resources, they actively develop characteristic planting and breeding, tourism and other advantageous industries. In view of the unreasonable industrial structures, underdeveloped areas also use the theories of ecology and circulation to optimize industrial systems, natural systems and social systems, reversing the inefficient industrial development mode. As a result, an environment-friendly and resource-saving industrial system is built to reduce environmental pollution and ecological damage, which promotes the healthy and sustainable development of the ecology, society and economy.

Due to the multidimensionality and complexity of poverty, a single antipoverty measure is difficult to completely achieve the goal of poverty eradication. Therefore, regional poverty alleviation is often a comprehensive system including a variety of measures. Through the mutual promotion and support of different targeted measures, the human-earth relationship 
in underdeveloped areas has been continuously optimized, forming a coordinated development situation between regional development and poverty alleviation. Specifically, according to the factors causing poverty, underdeveloped areas take a series of targeted measures to make up for their deficiencies in public services, human capital, industrial development and infrastructure. Meanwhile, they adhere to the unity of economic benefit, social benefit and ecological benefit, and use the concept of the ecologicalization of industry and the industrialization of ecology to build green production and living modes, constantly optimizing the element allocation, improving the structural organization and enhancing the functional status of human-earth system in underdeveloped areas. Thus, a mechanism and a system for the coordinated development of resource elements, environmental elements, human elements and economic elements are established to enhance the sustainable development ability of poor areas and poverty-stricken population. Furthermore, through the combination of targeted poverty alleviation, ecological conservation and sustainable development, underdeveloped areas continue to promote the transformation of regional development and the increase of poor's income, and finally achieve the goal of eliminating absolute poverty under the current standard (Figure 2).

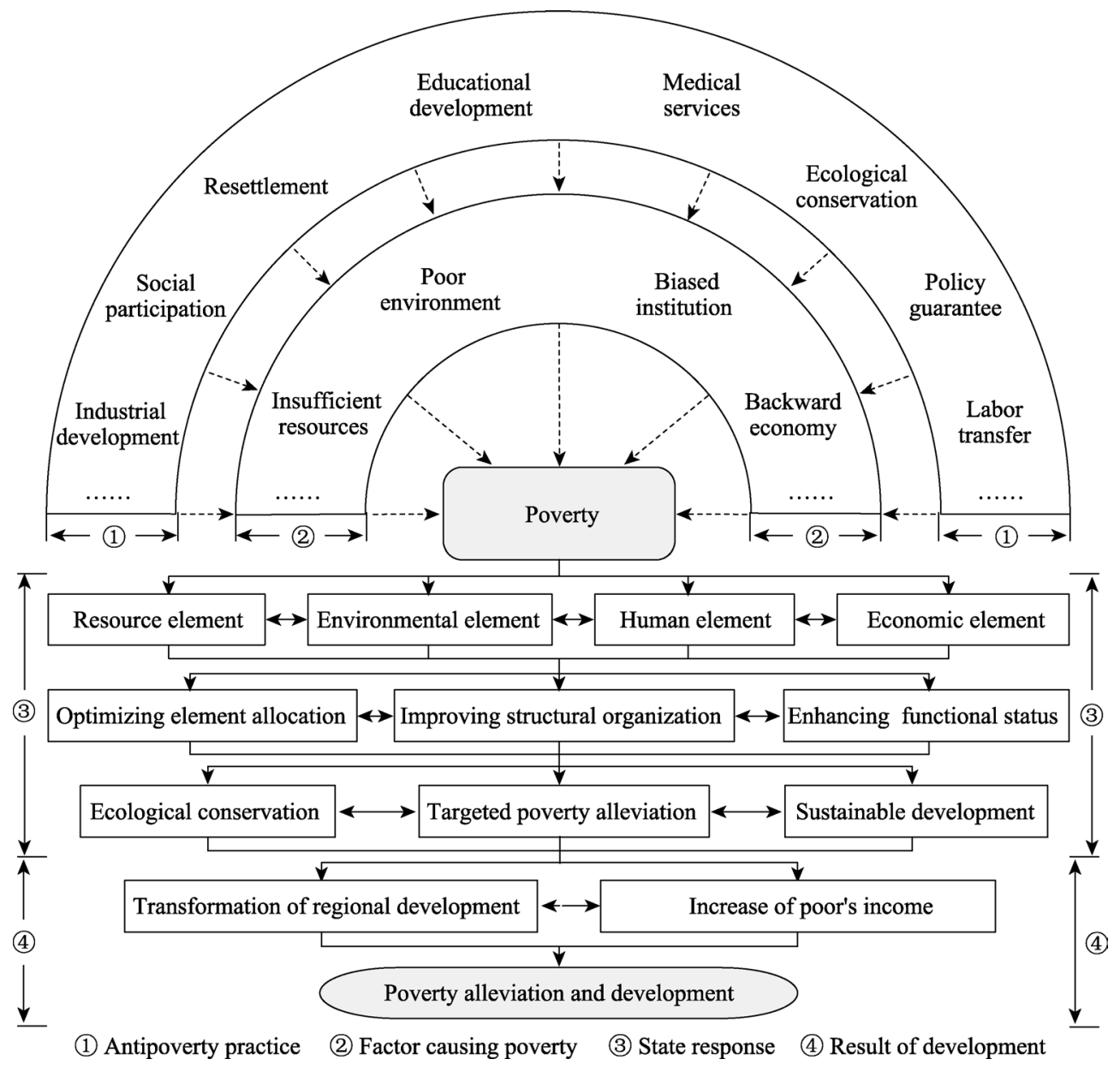

Figure 2 Mechanism of sustainable poverty alleviation and development in underdeveloped areas 


\section{Green development path and mode in underdeveloped areas}

The realization of the goal of poverty eradication in 2020 means the focus of social and economic development in underdeveloped areas has changed from low-level poverty alleviation to high-quality rural revitalization, which aims to promote regional development to a higher level through urban-rural integration (Guo et al., 2019; Guo and Liu, 2021). In terms of the characteristics of human-earth relationship, high-quality development needs to strengthen the construction of ecological civilization and form a green production and living pattern. Therefore, underdeveloped areas should make full use of preferential policies to form a green development mode and transform the ecological advantages into the advantages of regional development.

\subsection{Green development path}

Poverty alleviation and green development are two strategic choices to solve the main problems faced by underdeveloped areas in different development stages. The former focuses on the basic needs of the poor and takes comprehensive measures to govern multidimensional poverty, thus ensuring that the poor have no worries about food and clothing and that their needs for compulsory education, basic healthcare and safe housing are guaranteed. Green development is established on the basis of resources and environmental bearing capacity, and aims to promote the organic unity of beautiful ecology, thriving industry and rich people to realize regional high-quality development and the harmonious coexistence between human and earth. Therefore, the green development in underdeveloped areas must be established on the basis of eliminating poverty, that is, poverty alleviation is the foundation and premise of green development; on the other hand, green development enhances the endogenous growth momentum of the poor by strengthening the sustainable development ability of underdeveloped areas, which is the deepening and guarantee of poverty alleviation.

In the decisive stage of poverty alleviation, underdeveloped areas give full play to their comparative advantages, adjust policies and measures according to local conditions to promote the orderly flow of regional factors, overcome the long-standing problems of insufficient resources, poor environment, biased institution and backward economy, and preliminarily build a growth mechanism for regional sustainable development. Therefore, the process of poverty governance in underdeveloped areas is also a process of green development. In the new era, green development in underdeveloped areas needs to make full use of the foundation built in antipoverty stage, comprehensively analyzes the shortcomings of underdeveloped human-earth system, and promotes system reform and policy innovation. Through the system construction of "green land", "green people", "green industry" and "green right", the element allocation and structural organization of human-earth system will be further optimized. Finally, the advantages of ecological resources in underdeveloped areas will be effectively transformed into the advantages of regional development. "Green land" aims to create green territorial space through measures such as large-scale land greening action and ecological protection and restoration, and build efficient production space and livable living space. "Green people" aims to transform people into green producers and consumers through strengthening investments in modern green production skills and consumption patterns. "Green industry" aims to establish and improve a low-carbon and recycling industrial system by cultivating green industries and the service systems supporting the 
development of green industries. "Green right" aims to give full play to the role of market mechanism and realize the equal exchange of ecological products and services in underdeveloped areas through the innovation of green development mechanism and policy.

Based on the foundation built in the stage of poverty alleviation, green development is determined by the natural and human environments of underdeveloped areas. Through giving full play to the role of government, market, society and other subjects, underdeveloped areas realize the reasonable flow and optimal allocation of factors, and promote the construction of the "four green" system to practice the concept of the ecologicalization of industry and the industrialization of ecology. As a result, the deficiencies of underdeveloped areas in land, population, industry and rights will be constantly complemented, and the capacity, vitality, motivation and competitiveness of factors will be constantly activated. At the same time, underdeveloped areas will build a human-earth system with element integration, structure coupling and functional composite by the reconstruction of organization, industry and space, which is conducive to establish human-nature life communities and sustainable growth mechanisms and promote low-carbon, green and circular development of underdeveloped areas (Figure 3).

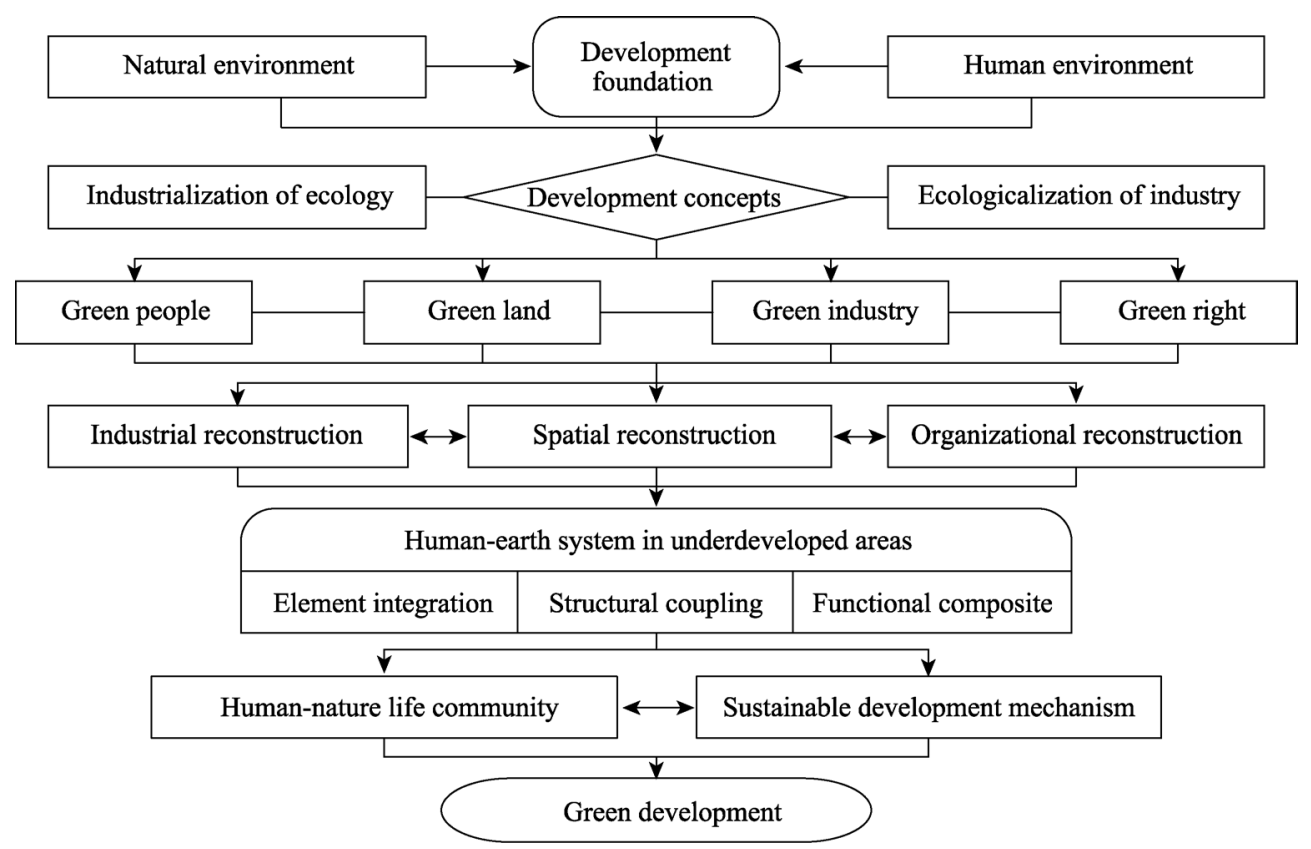

Figure 3 Path and mechanism of green development in underdeveloped areas

\subsection{Green development mode}

The period of the 14th Five-year Plan (2021-2025) is a key stage of China's social and economic transformation. However, the human-earth relationship in underdeveloped areas is still tense, which is highlighted by the huge resources and environmental pressure. Therefore, it is necessary to take ecological and environmental protection as the strategic focus, firmly establish and practice the concept of ecological civilization, and lead the green development of underdeveloped areas (Chang, 2018), thus realizing the transformation of development 
power, the innovation of growth mode and the optimization of economic structure. In the new era, underdeveloped areas should stick to the ecological conservation redline, deeply practice the concept that "clear waters and lush mountains are invaluable assets", innovate traditional socioeconomic development mode, and form a green development mode with regional characteristics, thus improving the quality and efficiency of regional development. In line with local conditions, the modes of "green land", "green people", "green industry" and "green right" are the main choices of green development in underdeveloped areas.

\subsection{1 "Green land" mode}

According to the national major function-oriented zone planning, maintaining ecological security as well as providing ecological goods and services to meet people's growing needs for a better life are the key tasks of underdeveloped areas. Therefore, underdeveloped areas should optimize territorial development pattern through ecological protection and construction, build a life community of mountains, water, forests, fields, lakes and grass, promote the harmonious coexistence of human and nature, and realize the goals of intensive production space, livable living space and beautiful ecological space (Figure 4). The key of ecological protection is to strictly implement the ecological function-oriented zone planning, clarify the major functions of different types of zones, and improve the ecological security pattern of underdeveloped areas. Also, it is necessary to strengthen ecological governance and control development intensity to effectively protect the ecology and improve the environment. Based on the principle of "natural recovery first and artificial restoration second", the purpose of ecological construction is to develop appropriate technologies to carry out large-scale land green action and promote the construction of various ecological function-oriented zones, thus solving the problem of unbalanced and insufficient land greening. Currently, programs such as returning farmland to forest and grassland (RFFG), Three-North Shelterbelt and Beijing-Tianjin Sandstorm Source Control are typical practices of the "green land" mode in China's underdeveloped areas.

Yan'an is located in the hilly and gully region of the Loess Plateau. For a long time, the local people have carried out predatory forest and grass cutting and land reclamation to meet their needs for survival and development, which results in serious deterioration of the ecology and environment. In this process, Yan'an has fallen into a vicious circle of poverty and reclamation, and become one of the areas with serious soil erosion in the middle reaches of the Yellow River. In 1999, the local government actively responded to the national call and implemented the project of RFFG. After more than 20 years of efforts, 718.3 thousand hectares of barren mountains in Yan'an have changed from "yellow" to "green", which plays an important role in water conservation and biodiversity protection. With the increase of vegetation and the improvement of ecology, the local air quality and soil

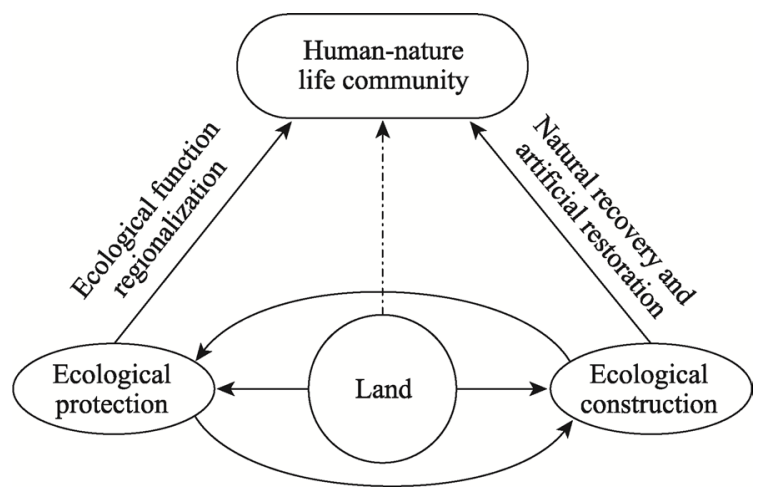

Figure 4 Mechanism of "green land" mode 
erosion have been greatly improved, and the ecological benefits continue to appear. Meanwhile, the local government actively carries out land consolidation in gully areas to solve the problem of "farmland and food shortage" caused by RFFG and consolidate the achievements of ecological construction. Besides, the high-quality production-living-ecological space generated by RFFG, gully management and land reclamation also give birth to the ecological economy and promote the vigorous development of green industries such as ecotourism and organic agriculture. As a result, the living standards of local people have significantly improved, and fundamental changes have taken place in their production and living modes, forming a "Yan'an model" for green poverty alleviation and development in central and western regions and old revolutionary base areas.

\subsection{2 "Green people" mode}

High-quality development is proposed to meet people's growing needs for a better life. Therefore, the green development in underdeveloped areas should adhere to the concept of people-oriented, and give full play to people's subjective initiative in source reduction, cleaner production, resource recycling and end-of-pipe treatment. By strengthening the training of people's green production knowledge and skills and deepening the green transformation of values and production mode, the working population are transformed into green producers, green operators and green managers. As a result, their ability to identify and grasp the changes in market demand, especially the demand for green products and services, will continue to increase, and their behavior damaging regional ecology and environment will continue to decrease. On the other hand, the concept of green consumption should be popularized to guide people to use green products and practice green travel and living, and people should strive to make these become their conscious behaviors. In addition, more attention should be paid to encouraging people to participate in voluntary service and fulfill the obligation of green development, thus forming a strong force for building a green lifestyle (Figure 5).

Pu'er is located in the southwest of Yunnan and belongs to the Border Mountainous Area of Western Yunnan. For a long time, poverty in Pu'er is featured by large number, deep degree as well as difficulty in getting rid of poverty. To reverse this situation, Pu'er has established the strategy of ecological city and green development based on its unique natural ad-

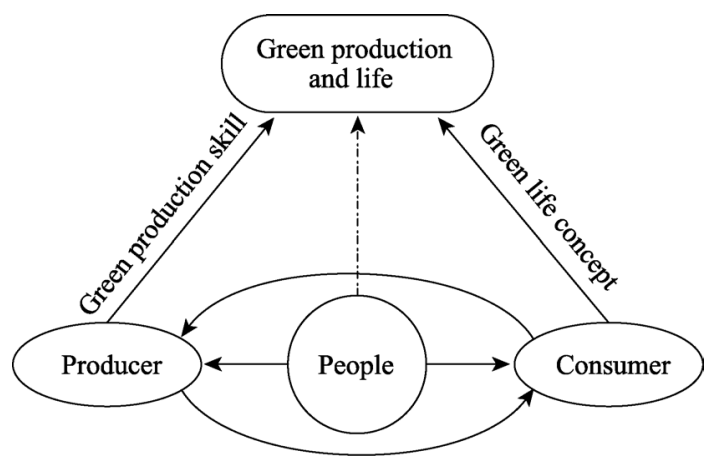

Figure 5 Mechanism of "green people" mode vantages. In terms of the system design, the government issued the green economic evaluation system and method, and incorporated the indicators of green economic development, resource utilization efficiency, environmental and ecological efficiency into the county comprehensive evaluation. To promote the sustainable development of green economy, the government has also made efforts to establish and improve the support system for green development from the aspects of policy, culture and platform construction. 
Meanwhile, the government has established a green standard evaluation system to promote the construction of green villages and towns, green communities, green schools and green hospitals, which makes green travel a conscious action of local people and green consumption a broad consensus of the whole society. As a result, a green production and consumption mode has gradually formed in the whole region, a good fashion of respecting, adapting to and protecting nature has formed in the entire society, and the mutual-promotion mechanism of ecological construction and regional development has been continuously improved, which has become a strong driving force for green and high-quality development. In 2013, Pu'er was identified as the first green economy experimental demonstration zone in China by the National Development and Reform Commission, and passed the mid-term evaluation in 2018.

\subsection{3 "Green industry" mode}

Entering the third decade of the 21 st century, the focus of regional development in underdeveloped areas has shifted to improving the quality of social and economic development. Therefore, it is necessary to establish the concept of "ecological priority and green development" to promote the transformation and upgrading of economic development mode, and improve the low-carbon and recycling industrial system through the ecologicalization of industry and the industrialization of ecology (Figure 6). Following the principles of "green, recycling, low-carbon and sustainable", technology should be continuously improved to develop emerging industries with high resource-utilization efficiency, low energy consumption and good ecological benefits. Meanwhile, appropriate technologies need to be adopted to transform traditional industries, promote the optimization and upgrading of industrial structure and product structure, and improve the quality and efficiency of industrial development. On the other hand, the concept of industrialization is needed to be taken to promote ecological construction, and more diversified ecological products and services should be provided for underdeveloped areas and their related areas in the way of socialized production and market-oriented operation. As a result, ecological products and services are effectively transformed into production factors and material wealth, which promote ecological protection and construction and form a benign mechanism for the mutual promotion of ecological construction and economic development.

Yangxian is a poverty-stricken county located in southwest of Shaanxi and the eastern Hanzhong Basin. As a county with two national natural reserves, Yangxian is known as one of the areas with the best ecology along the same latitude of the earth, which provides a unique advantage for the county to develop green industry. In 2013, Yangxian put forward the strategy of "ecological county" and established the development concept of "both development and ecology". To promote the implementation of this strategy, the county takes organic and

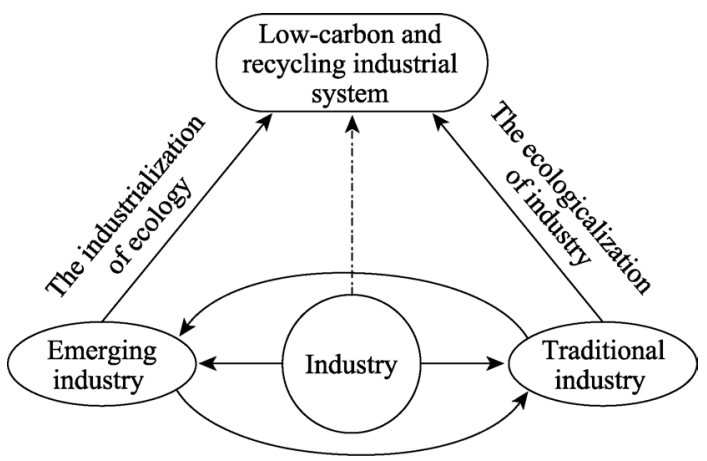

Figure 6 Mechanism of "green industry" mode 
circular industries as the development direction, and constructs a resource-saving and environment-friendly industrial system to realize input reduction, clean production and waste recycling. As a result, the comprehensive industrial benefits have been continuously improved, and the sustainable development ability of Yangxian has been significantly enhanced, which effectively promotes the county's decisive fight against poverty. In 2016, Yangxian was awarded the "national organic product certification demonstration zone" by Certification and Accreditation Administration of the People's Republic of China. After years of development, Yangxian has built the largest organic industrial cluster in northwest China, and the output value of organic industry accounts for more than $80 \%$ of county gross agricultural output value, which helps the county achieve the goal of eliminating absolute poverty at current standard in 2020. To meet the needs of regional transformation in the new era, green organic industry provides an important path for Yangxian to consolidate and expand antipoverty achievements and promote high-quality development during the period of the 14th Five-year Year Plan (2021-2025).

\subsection{4 "Green right" mode}

Underdeveloped areas have the comparative advantage of rich ecological resources. However, due to the biased policy and the lack of ecological concept, the unreasonable utilization of ecological resources in underdeveloped areas is common. Accordingly, the private and social marginal incomes and private and social marginal costs of the utilization of ecological resources deviate seriously (Sun, 2017). In this context, underdeveloped areas should give full play to the role of government and market, innovate the value realization mechanism of ecological resources, and transform the regional development mode through the equity of ecological assets (Figure 7). On the basis of clarifying the major functions of different zones, the ecological compensation mechanism and interest linking-sharing mechanism between underdeveloped and developed areas need to be improved through measures such as counterpart cooperation, industrial transfer and co-construction of industrial parks. Also, it is urgent to carry out the pilot of ecological compensation taxes at the right moment. On the other hand, more attention should be paid to building a market-oriented trading platform for ecological products and services, deepening the innovation of green development system, and implementing typical practices such as forest bank, water bank and wetland mitigation bank to realize ecological value, thus boosting interregional ecological compensation through ecological ownership transaction. As a result, the trading mechanism of green rights

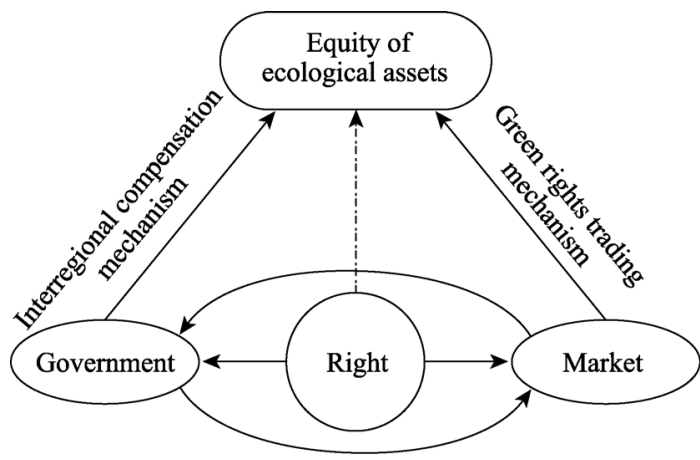

Figure 7 Mechanism of "green right" mode and interests will be continuously improved to transform ecological advantages into the advantages of regional development and effectively protect the rights and interests of all parties.

In 2018, Chongqing municipal people's government issued the "Implementation Plan for Chongqing Territorial Greening Improvement Action (2018-2020)", which aimed to build an important ecological barrier in the upper reaches of the Yangtze 
River and realize the protection and appreciation of natural resources. To effectively implement this plan, the government takes the forest coverage rate as the binding index to conduct a unified assessment for each district and county. According to the differences in natural conditions, major functions and other aspects of each county, the target value of forest coverage rate is divided into three levels. For the counties with difficulty to achieve the required forest coverage rate, it is allowed to obtain the forest area index in the form of purchase and include it when calculating the forest coverage rate of the county, thus forming the transaction demand between counties with the forest coverage rate greater than the specified value and counties with the forest coverage rate less than the specified value. Meanwhile, the government also issued a work plan to build a trading platform for the forest coverage index, and explored and established a value realization mechanism of ecological products and services based on the index trading of forest coverage rate. Therefore, counties that actively promote environmental construction and ecological protection can get corresponding compensation and do not suffer loss. As a result, Chongqing has opened up channels to realize the value of ecological products and services, promoted the construction of a long-term mechanism of ecological priority and green development, and formed a virtuous circle of ecological protection and regional development.

\section{Discussion}

Building a moderately prosperous society in an all-round way in 2020 indicates that China has entered a new stage of building a socialist modern country in an all-round way (Guo and Liu, 2021; Hu et al., 2021; Xie, 2021). Accelerating the development of underdeveloped areas to narrow the regional gap has become the priority goal of current national major strategy, and is also the inevitable requirement to promote regional coordinated development in the new era (Wang, 2017; Fan et al., 2020). To achieve this goal, it is necessary to improve regional cooperation and mutual assistance mechanism and interregional interest compensation mechanism to provide strong support for the development of underdeveloped areas such as old revolutionary base areas, ethnic minority areas and ecologically fragile areas. On the other hand, a comprehensive coordination mechanism involving multi-level management subjects of province-city-county-township-village needs to be established to promote the modernization of governance system and governance capacity in underdeveloped areas. In addition, more attention should be paid to promote the organic combination of rural revitalization and new-type urbanization, and build a driving force for sustainable poverty alleviation and green development in underdeveloped areas through urban-rural integrated development.

Due to the persistence of unbalanced and inadequate development, the relative poverty in underdeveloped areas is inevitable (Dong et al., 2021), which is manifested in insufficient demand guarantee, maladjustment in the process of social and economic transformation, structural social barriers, etc. (Guo et al., 2018; Li and Xu, 2018; Zuo and Su, 2020). Accordingly, underdeveloped areas should maintain the continuity of antipoverty policies to achieve the stability of poverty alleviation and promote regional development to a higher level. On the other hand, as socialism construction with Chinese characteristics enters a new era, the focus of regional development has transformed from high-speed to high-quality (Jin, 2018), which inherently requires strengthening the implementation of ecological civilization 
and promoting green development to help underdeveloped areas achieve sustainable poverty alleviation and realize the effective connection between poverty alleviation and rural revitalization. Therefore, there is a close logical relationship between sustainable poverty alleviation and green development, and the process of green development in underdeveloped areas is also the process of sustainable poverty alleviation. Specifically, green development transforms regional ecological advantages into economic growth advantages and promotes the efficiency and harmony of regional human-earth system through optimizing territorial spatial pattern and industrial structure. Therefore, it is an important way of sustainable poverty alleviation in underdeveloped areas. Sustainable poverty alleviation aims to steadily increase personal income and construct a regional endogenous growth mechanism through making up for the deficiencies of human, economic, resource and environmental elements, and is the fundamental goal of green development in underdeveloped areas.

As the main path and mode of sustainable poverty alleviation and green development, green people, green land, green industry and green right respectively reflect the subject construction, ecological construction, economic construction and institutional construction of regional development in underdeveloped areas. Specifically, "green people" is an important measure of subject construction, which focuses on the green transformation of human capital to strengthen people's green ability and activate regional factor endowment. "Green land" is the primary task of ecological construction, which focuses on promoting environmental conservation and ecological construction to improve the ecology, beautify the environment and improve production and living conditions. "Green industry" is the fundamental requirement of economic construction, which focuses on tapping resource advantages to construct a green industrial system and provide ecological products and services to meet people's needs for a better life. "Green right" is an important guarantee for institutional construction, which focuses on establishing and improving the value realization mechanism of ecological products and services and promote the industrialization of ecology and the ecologicalization of industry. Given the analysis above, "green people", "green land", "green industry" and "green right" are closely linked to jointly support sustainable poverty reduction and green development in underdeveloped areas. Due to the comprehensiveness of sustainable poverty reduction and green development, it is difficult to achieve the goal of high-quality development in underdeveloped areas by a single path. Therefore, the measures of green people, green land, green industry and green right should be integrated to build a "four in one" path system, thus optimizing the human-earth coupling and interaction in underdeveloped areas and promoting the construction of sustainable endogenous growth momentum.

\section{Conclusions}

This study analyzes the characteristics of underdeveloped areas from the perspective of human-earth system, discusses the sustainable antipoverty practice and mechanism in underdeveloped areas, and proposes the path selection and theoretical mode of green development in underdeveloped areas to guide the high-quality development of China's underdeveloped areas. The main conclusions are as follows:

(1) Regional human-earth system is an organic whole with specific structure and function, and is formed by the coupling of human, economic, resource and environmental elements 
according to certain rules in a specific geographical space. As a negative result in the evolution of human-earth system, the root of underdeveloped areas lies in the lack of long-term mechanism of human-earth coupling and coordination and the fact that regional ecological advantages have not been transformed into development advantages, and is featured by insufficient resources, poor environment, biased institution and backward economy.

(2) In the crucial stage of poverty alleviation, China's underdeveloped areas have formed a sustainable antipoverty practice system with the main contents of industrial development, labor transfer, resettlement, educational development, medical services, ecological construction, policy guarantee, social participation, etc. Through the combination of policies, underdeveloped areas continue to make up for their shortcomings, steadily promote the ecologicalization of industry and the industrialization of ecology, and initially build a coupling and coordinated development mechanism of human, economic, resource and environmental elements, which is conducive to the organic combination of targeted poverty alleviation, ecological conservation and sustainable development, and realizing the transformation of regional development and the increase of poor's income.

(3) Based on the foundation of poverty alleviation and the transformation of national major strategies, green development aims to transform the ecological advantages of underdeveloped areas into the advantages of regional development. Through the optimal allocation of elements, it will help underdeveloped areas make best use of theirs advantages and bypass the disadvantages, and promote the reconstruction of organization, industry and space, forming a sustainable growth mechanism and human-nature life community. In addition, green development mode with regional characteristics, which mainly includes "green land", "green people", "green industry" and "green right", will be built to achieve the high-quality development of underdeveloped areas.

Currently, the world is undergoing great changes that have never been experienced in the past century, and the global COVID-19 epidemic has accelerated these changes (Liu et al., 2020b). Correspondingly, the domestic and international environment facing China's development is also undergoing complex and profound changes (Oldekop et al., 2020; Wang, 2020). In this context, underdeveloped areas should pay more attention to understanding the new development stage, implementing the new development concept, integrating into the new development pattern, creating new development advantages, striving to seeking opportunities in the crisis and creating a new situation in the change. Through system reform and policy innovation, underdeveloped areas will form an internal circulation with two-way free flow of industrial-agricultural factor and urban-rural factor as the main content, build a mutual circulation with surrounding areas, and integrated into national and international circulations, thus promoting the sustainable poverty alleviation and green development of underdeveloped areas and constructing a new development pattern with the domestic circulation as the main body and the domestic and international circulation promoting each other.

\section{References}

Alkire S, Foster J, 2011. Counting and multidimensional poverty measurement. Journal of Public Economics, 95(7/8): 476-487.

Alkire S, Foster J, Seth S et al., 2015. Multidimensional Poverty Measurement and Analysis. New York: Oxford University Press. 
An C, 2019. International cooperation on poverty reduction in Africa within framework of global poverty management. Contemporary World, (10): 23-28.

Brainard L, Chollet D, 2007. Too Poor for Peace? Global Poverty, Conflict, and Security in the 21st Century. Washington, D.C.: Brookings Institution Press.

Cheng Y, 2006. Optimized regulation model of human-earth system based on system dynamics. Journal of University of Chinese Academy of Sciences, 23(1): 83-90. (in Chinese)

Cobbinah P B, Black R, Thwaites R, 2013. Dynamics of poverty in developing countries: Review of poverty reduction approaches. Journal of Sustainable Development, 6(9): 25-35.

Combes P P, Mayer T, Thisse J F, 2008. Economic Geography. Princeton and Oxford: Princeton University Press.

Copestake J, Camfield L, 2010. Measuring multidimensional aspiration gaps: A means to understanding cultural aspects of poverty. Development Policy Review, 28(5): 617-633.

Deinne C E, Ajayi D D, 2021. Dynamics of inequality, poverty and sustainable development of Delta State, Nigeria. GeoJournal, 86(1): 431-443.

Dong X, Jin G, Deng X et al., 2021. Multidimensional measurement of poverty and its spatio-temporal dynamics in China from the perspective of development geography. Journal of Geographical Sciences, 31(1): 130-148.

Duraiappah A K, 1998. Poverty and environmental degradation: A review and analysis of the nexus. World Development, 26(12): 2169-2179.

Fan J, Sun W, Zhou K et al., 2012. Major function-oriented zone: New method of spatial regulation for reshaping regional development pattern in China. Chinese Geographical Science, 22(2): 196-209.

Fan J, Zhou K, Wu J, 2020. Typical study on sustainable development in relative poverty areas and policy outlook of China. Bulletin of the Chinese Academy of Sciences, 35(10): 1249-1263. (in Chinese)

Faust J, 2010. Policy experiments, democratic ownership and development assistance. Development Policy Review, 28(5): 515-534.

Fransman T, Yu D, 2019. Multidimensional poverty in South Africa in 2001-16. Development Southern Africa, 36(1): 50-79.

Fu R, Jin G, Chen J et al., 2021. The effects of poverty alleviation investment on carbon emissions in China based on the multiregional input-output model. Technological Forecasting and Social Change, 162: 120344.

Ge D, Lu Y, 2021. A strategy of the rural governance for territorial spatial planning in China. Journal of Geographical Sciences, 31(9): 1349-1364.

Gong H, Meng D, Li X et al., 2013. Soil degradation and food security coupled with global climate change in northeastern China. Chinese Geographical Science, 23(5): 562-573.

Guo Y, Liu Y, 2021. Poverty alleviation through land assetization and its implications for rural revitalization in China. Land Use Policy, 105: 105418.

Guo Y, Wang J, 2021. Poverty alleviation through labor transfer in rural China: Evidence from Hualong County. Habitat International, 116: 102402.

Guo Y, Zhou Y, Cao Z, 2018. Geographical patterns and anti-poverty targeting post-2020 in China. Journal of Geographical Sciences, 28(12): 1810-1824.

Guo Y, Zhou Y, Liu Y, 2019a. Targeted poverty alleviation and its practices in rural China: A case study of Fuping county, Hebei Province. Journal of Rural Studies, https://doi.org/10.1016/j.jrurstud.2019.01.007

Guo Y, Zhou Y, Liu Y, 2019b. Targeted poverty alleviation and rural revitalization in poverty-stricken areas: Internal logic and mechanism. Geographical Research, 38(12): 2819-2832. (in Chinese)

He S, Bayrak M M, Lin H, 2017. A comparative analysis of multi-scalar regional inequality in China. Geoforum, 78: $1-11$.

Hu A, Yan Y, Tang X et al., 2021. 2050 China: Strategic goals and two stages. In: 2050 China. Singapore: Springer, 45-60.

Jin B, 2018. Study on the "high-quality development" economics. China Political Economy, 1(2): 163-180.

Li X, Xu H, 2018. Several thoughts on the poverty issue after 2020. Journal of Chinese Academy of Governance, (1): 62-66. (in Chinese)

Li X, Yang Y, Liu Y, 2017. Research progress in man-land relationship evolution and its resource-environment base in China. Journal of Geographical Sciences, 27(8): 899-924.

Liu Y, 2020. Modern human-earth relationship and human-earth system science. Scientia Geographica Sinica, 40(8): 1221-1234. (in Chinese)

Liu Y, Guo Y, Zhou Y, 2018. Poverty alleviation in rural China: Policy changes, future challenges and policy im- 
plications. China Agricultural Economic Review, 10(2): 241-259.

Liu Y, Liu J, Zhou Y, 2017. Spatio-temporal patterns of rural poverty in China and targeted poverty alleviation strategies. Journal of Rural Studies, 52: 66-75.

Liu Y, Zang Y, Yang Y, 2020a. China's rural revitalization and development: Theory, technology and management. Journal of Geographical Sciences, 30(12): 1923-1942.

Liu Y, Zhang X, Li X et al., 2003. Mechanism and regulation of land degradation in Yulin district. Journal of Geographical Sciences, 13(2): 217-224.

Liu Y, Zhou Y, Liu J, 2016. Regional differentiation characteristics of rural poverty and targeted poverty alleviation strategy in China. Bulletin of Chinese Academy of Sciences, 31(3): 269-278. (in Chinese)

Liu Z, Zhang Y, Wang X, et al., 2020b. Recommendations for surgery during the novel coronavirus (COVID-19) epidemic. Indian Journal of Surgery, 82(2): 124-128.

Luo Q, Luo L, Zhou Q et al., 2019. Does China's Yangtze River Economic Belt policy impact on local ecosystem services? Science of The Total Environment, 676: 231-241.

Matsuyama K, 2010. Poverty traps. In: Economic Growth. London: Palgrave Macmillan, 215-221.

Misturelli F, Heffernan C, 2010. The concept of poverty: A synchronic perspective. Progress in Development Studies, 10(1): 35-58.

Oldekop J A, Horner R, Hulme D et al., 2020. COVID-19 and the case for global development. World Development, 134: 105044 .

Oluwatayo I B, Ojo A O, 2018. Walking through a tightrope: The challenge of economic growth and poverty in Africa. The Journal of Developing Areas, 52(1): 59-69.

Sun Z, 2017. Approaching method and mechanism construction of ecological value. Bulletin of Chinese Academy of Sciences, 32(1): 78-84. (in Chinese)

Ujunwa A, Okoyeuzu C, Kalu E U, 2019. Armed conflict and food security in West Africa: Socioeconomic perspective. International Journal of Social Economics, 46(2): 182-198.

United Nations (UN), 2015. Transforming Our World: The 2030 Agenda for Sustainable Development. New York: United Nations.

Wang Y, 2017. Implementing the strategy of regional coordinated development. Economic Daily, 2017-11-16. (in Chinese)

Wang Y, 2020. Changes unseen in a century, high-quality development, and the construction of a new development pattern. Management World, 36(12): 1-13. (in Chinese)

Wang Y, Liu Y, Li Y et al., 2016. The spatio-temporal patterns of urban-rural development transformation in China since 1990. Habitat International, 53: 178-187.

World Bank, 2016. The World Bank Group A to Z 2016. World Bank Publications.

Wu C, 1991. The core of geographical research: Human-earth areal system. Economic Geography, 11(3): 1-6.

Xie F, 2021. The theory and practice of completing a moderately prosperous society in all respects. Social Sciences in China, 42(3): 4-23.

Yang D, 1990. Patterns of China's regional development strategy. The China Quarterly, 122: 230-257.

Yang W, 1997. Analysis on the definition and characteristics of underdeveloped areas in China. Macroeconomics, (4): 52-55. (in Chinese)

Yu H, Xing L, 2021. Analysis of the spatiotemporal differences in the quality of marine economic growth in China. Journal of Coastal Research, 37(3): 589-600.

Zhou K, Fan J, 2015. Characteristics and influence factors of resources and environment carrying capacity in underdeveloped areas of China. Geographical Research, 34(1): 39-52. (in Chinese)

Zhou Y, Guo Y, Liu Y et al., 2018. Targeted poverty alleviation and land policy innovation: Some practice and policy implications from China. Land Use Policy, 74: 53-65.

Zhou Y, Li Y, Liu Y, 2020. The nexus between regional eco-environmental degradation and rural impoverishment in China. Habitat International, 96: 102086.

Zhou Y, Liu Y, 2019. The geography of poverty: Review and research prospects. Journal of Rural Studies, https://doi.org/10.1016/j.jrurstud.2019.01.008

Zuo T, Su W, 2020. Strategic orientation and policy option on the governance of relative poverty in the context of rural revitalization. Journal of Xinjiang Normal University (Philosophy and Social Sciences), 41(4): 88-96. (in Chinese) 